\title{
Remarkable Predominance of a Small Number of Genotypes in Greenhouse Populations of Botrytis cinerea
}

\author{
Marc Bardin, Véronique Decognet, and Philippe C. Nicot
}

INRA, UR407 Pathologie végétale, F-84140 Montfavet, France.

Accepted for publication 2 February 2014.

\begin{abstract}
Bardin, M., Decognet, V., and Nicot, P. C. 2014. Remarkable predominance of a small number of genotypes in greenhouse populations of Botrytis cinerea. Phytopathology 104:859-864.

Although Botrytis cinerea is known for its ability to produce high amounts of spores on diseased plants, enabling it to complete rapidly numerous developmental cycles in favorable environments, population genetics studies of this fungus indicate enormous diversity and limited clonal spread. Here, we report an exception to this situation in the settings of commercial tomato greenhouses. The genotypic characterization of

development of gray mold epidemics in four greenhouses in southern France, revealed the presence of a few predominant genotypes in a background of highly diverse populations. The comparison of genotypic profiles for isolates collected in the air or on the plants was compatible with the hypothesis of an entry in the greenhouse of substantial amounts of inoculum from the outside environment but it also highlighted the importance of secondary inoculum produced within the crop. The overall results of this work suggest that sporulation could be an important target for disease management strategies in the greenhouse.
\end{abstract} 712 isolates collected from the air and from diseased plants, following the

The plant-pathogenic fungus Botrytis cinerea (teleomorph: Botryotinia fuckeliana) remains a serious problem on many crops. Although much effort has been dedicated to understanding the disease it causes (gray mold), certain epidemiological aspects still remain unclear. One such key question is the origin and dispersion patterns of inoculum in various cropping systems. Some information has been provided by population genetics studies of this haploid ascomycete. Most of these studies have described high levels of genetic diversity and concluded that populations of Botrytis cinerea have a very limited clonal spread $(3,14,21,34)$. These reports of a general lack of clonality in field populations of $B$. cinerea contrast with the fact that this fungus can rapidly produce millions of conidia on a variety of substrates (28). These anemophilic spores are easily dispersed by wind and turbulent air currents (18) and may allow the fungus to complete a high number of developmental cycles (substrate colonization, sporulation, and dispersion) in a short time.

In other airborne plant-pathogenic fungi with an abundant production of anemophilic spores, clonality can be very important. For example, Venturia inaequalis populations show a clonal structure for isolates originating from apple cultivars with the resistance gene $V f(17)$. A high rate of clonal reproduction was also clearly demonstrated for the wheat leaf rust Puccinia triticina (16). In the case of $B$. cinerea, one study conducted in controlled conditions hinted at the possibility that clonal populations could develop in greenhouse production systems. Following the introduction of two strains of $B$. cinerea with known genetic profiles in four disease-free experimental greenhouse compartments, a rapid and massive modification in the genetic structure of the popu-

Corresponding author: P. C. Nicot; E-mail address: Philippe.Nicot@avignon.inra.fr

* The $\boldsymbol{e}$-Xtra logo stands for "electronic extra" and indicates that the online version contains one supplementary figure.

http://dx.doi.org/10.1094/PHYTO-10-13-0271-R

(c) 2014 The American Phytopathological Society
Additional keywords: airborne inoculum, Botryotinia fuckeliana. lations was observed (6). The frequency of genetic profiles representing the introduced strains rose from 0 to $66 \%$ (among 353 isolates sampled from the air) 2 weeks after introduction, and reached $91 \%$ (among 240 isolates collected from diseased plants) 45 days later. The predominance of these two genetic profiles in the four experimental greenhouse compartments led to the hypothesis that airborne inoculum in a greenhouse may be mostly provided by secondary inoculum produced on diseased plants, rather than by air spora entering from the outside. In commercial greenhouse production, although knowledge of the origin of inoculum would be useful to devise disease control strategies, such information is still lacking.

The overall objective of the present study was to investigate whether endogenous secondary inoculum of $B$. cinerea may also be important in commercial tomato greenhouses. To this end, we characterized 712 isolates from four greenhouses on two sampling sites in southern France, using microsatellite markers, and carried out population genetics analyses. Three main questions were addressed. (i) Can we observe a predominance of certain genetic profiles among isolates collected within a greenhouse? (ii) Are the populations present in two neighboring greenhouses genetically more similar than populations sampled in distant greenhouses? (iii) Are there differences among subpopulations sampled from plants and those from the air inside a greenhouse?

\section{MATERIALS AND METHODS}

Experimental setup. Populations of $B$. cinerea were studied in greenhouses located on two sites in southern France chosen for their regular occurrence of gray mold epidemics. On each site, isolates were collected from two similar, adjacent greenhouse structures (located $10 \mathrm{~m}$ apart) to assess on-site variability. On both sites, tomato plants were grown in soil and fertigated with a drip-irrigation system. The plants were first produced in a nursery and installed in the greenhouses as $\approx 1$-month-old seedlings. On one site, located in L'Isle-sur-la-Sorgue (GPS: N 43 53' 59.839"; E $\left.5^{\circ} 2^{\prime} 15.144^{\prime \prime}\right)$, the greenhouses under study consisted of heated commercial glasshouses in which air circulation was achieved 
through fan jet systems. In these two glasshouses (referred to as G1 and G2 in the rest of this article), the plants were installed in January with a density of 2.5 plants $\mathrm{m}^{-2}$ over a surface of $5,800 \mathrm{~m}^{2}(\mathrm{G} 1)$ and $3,200 \mathrm{~m}^{2}(\mathrm{G} 2)$. Treatments with anti-Botrytis fungicides were presumably carried out by the grower but this specific information was not disclosed. The other site was located in Alenya (GPS: N 42 38' 22.038'"; E $2^{\circ} 58^{\prime} 50.606^{\prime \prime}$ ), at a distance of $220 \mathrm{~km}$ from the first site, in an experimental unit of the French National Institute for Agricultural Research (INRA). On this site, the two greenhouses under study consisted of unheated tunnels (T1 and T2; $217 \mathrm{~m}^{2}$ each). Plants were installed in each tunnel in February, with a plant density of 2.0 plants $\mathrm{m}^{-2}$. Throughout the season, crop management in these experimental greenhouses was conducted in a way similar to that of commercial production.

Isolate collection and microsatellite marker genotyping. In each greenhouse, 120 samples of diseased plant tissue were collected at random from stem lesions 5 months (L'Isle-sur-la-Sorgue) or 4 months (Alenya) after planting, following the development of gray mold epidemics. A fragment of the lesion was excised with sterilized forceps and placed on potato dextrose agar (PDA) (Difco Laboratory, Becton, Dickinson \& Co., Sparks, MD) medium. The plates were carried back to the laboratory and incubated at room temperature for 2 to 3 days until typical mycelium of $B$. cinerea was observed. The isolates were then transferred to fresh medium to obtain pure cultures.

During the sampling campaign in the greenhouses, isolates were also collected from the airborne inoculum. In each structure, 50 petri plates $(9 \mathrm{~cm}$ in diameter) containing a Botrytis-selective medium (8) were placed in a regular pattern on the floor and exposed for $24 \mathrm{~h}$. The plates were then carried back to the laboratory and incubated at room temperature. For each greenhouse, isolates were taken from a random sample of 100 colonies (whenever possible) and transferred to PDA medium.

After purification, a single-spore culture was prepared for each isolate and mycelium was produced and lyophilized as described by Decognet et al. (6). Genomic DNA was extracted from aliquots of $15 \mathrm{mg}$ of lyophilized fungal material using 96-well plates, according to the Dneasy Plant extraction Kit (Qiagen, Chatsworth, CA). The nine microsatellite markers developed for $B$. cinerea (15) were amplified separately with forward primers conjugated with fluorescent dyes IRD-700 or IRD-800 (MWGBiotech, Courtaboeuf, France) and electrophoresed on a LI-COR $\mathrm{IR}^{2}$ (LI-COR Biosciences, Lincoln, NE) sequencer, as described by Decognet et al. (6). SAGA ${ }^{\mathrm{GT}}$ software (LI-COR Biosciences) was used for the allele analysis. The analysis was conducted on isolates for which amplification of a single allele was obtained for each of the nine microsatellite markers. The allele sizes of these nine loci were combined to assign a genotypic profile to each isolate, referred to in the rest of the article as "haplotype".
Genetic diversity within populations. For analysis purposes, we considered separately the groups of isolates collected from diseased plants and those collected simultaneously from the air in a given greenhouse. Thus, we distinguished a total of eight subpopulations (Table 1), each composed of $\approx 100$ individuals (with the exception of the air population in greenhouse G2, for which only 18 isolates could be collected). For each of these subpopulations, the frequency of each haplotype was calculated and various criteria were used to assess diversity.

Genetic diversity was characterized by assessing allelic richness $\left(\mathrm{N}_{\mathrm{a}}\right.$, mean number of alleles per locus) and computing Nei's gene diversity index (27) using the program ARLEQUIN, version 3.1 (11). Haplotypic diversity was estimated for each population by computing the G index of Stoddart and Taylor (33) and the evenness using the GenoDive software (25). Additionally, we computed the multilocus linkage disequilibrium index $r_{\mathrm{d}}(1)$. This index takes a value of 0 in the absence of linkage disequilibrium and increases with increasing disequilibrium. For the statistical analysis, observed values were compared with the results of 1,000 randomizations of alleles (14).

Genetic differentiation between populations. Genetic differentiation between populations was estimated by calculating pairwise Weir and Cockerham's $F_{\text {ST }}$ values (35) using ARLEQUIN. The significance level for the population pairwise values was determined after 1,023 permutations and a sequential Bonferroni correction of the $P$ values was used to correct multiple tests (31). ARLEQUIN was also used for a hierarchical analysis of molecular variance (AMOVA) among populations.

\section{RESULTS}

Occurrence of predominant haplotypes in a background of highly diverse populations. In total, 112 distinct haplotypes were observed among the 712 isolates characterized from tomato greenhouses in this study (Table 1). A clear predominance of certain haplotypes was observed on both sampling sites (Table 2). In Alenya, one haplotype (H69) was highly predominant, with frequencies of $\approx 48$ and $\approx 80 \%$ of isolates characterized in tunnels $\mathrm{T} 1$ and T2, respectively. In L'Isle-sur-la-Sorgue, two haplotypes (H2 and H9) represented $36 \%$ of isolates characterized in glasshouse $\mathrm{G} 1$ and three haplotypes $(\mathrm{H} 2, \mathrm{H} 3$, and $\mathrm{H} 94)$ represented $59 \%$ of isolates characterized in glasshouse G2.

This predominance of a few haplotypes was accompanied in all cases by a high level of diversity among the remaining isolates, as shown by the high number of distinct haplotypes identified on each site and the high number of haplotypes represented by a single isolate (Table 1). Haplotypic diversity, assessed by the index of evenness and by the $\mathrm{G}$ index of Stoddart and Taylor, was remarkably higher in L'Isle-sur-la-Sorgue than in Alenya, suggesting possible differences between those two sites in terms of

TABLE 1. Haplotypic diversity in populations of Botrytis cinerea sampled from the air and from diseased plants in four greenhouses on two sites in southern France

\begin{tabular}{|c|c|c|c|c|c|c|c|c|}
\hline \multirow{3}{*}{ Parameters of examination } & \multicolumn{8}{|c|}{ Sites, greenhouses, origin of isolates } \\
\hline & \multicolumn{4}{|c|}{ Alenya } & \multicolumn{4}{|c|}{ L'Isle-sur-la-Sorgue } \\
\hline & \multicolumn{2}{|c|}{ T1 } & \multicolumn{2}{|c|}{$\mathrm{T} 2$} & \multicolumn{2}{|c|}{ G1 } & \multicolumn{2}{|c|}{ G2 } \\
\hline Number of isolates & 98 & 100 & 97 & 100 & 99 & 100 & 100 & 18 \\
\hline \multicolumn{9}{|l|}{ Number of detected haplotypes ${ }^{a}$} \\
\hline Whole study & \multicolumn{8}{|c|}{$112(66)$} \\
\hline$G$ index ${ }^{\mathrm{b}}$ & 3.87 & 3.50 & 1.43 & 1.59 & 13.86 & 8.01 & 6.81 & 4.15 \\
\hline Evenness & 0.15 & 0.15 & 0.13 & 0.10 & 0.37 & 0.29 & 0.40 & 0.59 \\
\hline
\end{tabular}

a Numbers in parentheses = numbers of haplotypes represented by a single isolate.

b Stoddart and Taylor's $G$ index. 
the sources of primary inoculum and the dynamics of the epidemics. Thus, differences in genetic structure between these two sampling sites were examined more closely.

Substantial genetic differentiation between sampling sites. When comparing the two sampling sites, 8 haplotypes were shared among the 112 detected in the study (Table 2). They represented 355 isolates, amounting to $50 \%$ of those characterized. One striking difference between the two sites was the identity and frequency of observation of the predominant haplotypes. For example, the haplotype highly predominant in Alenya (H69) was rare in L'Isle-sur-la-Sorgue. Conversely, haplotype H2, which was predominant in L'Isle-sur-la-Sorgue, was rare in Alenya.

This difference between sites was confirmed by the results of $F_{\text {ST }}$ analyses. The $F_{\text {ST }}$ values were higher (with one exception) for comparisons of subpopulations from different sites than for comparisons of those from the same site (Table 3 ). The results of AMOVA analyses were consistent with those of $\mathrm{F}_{\mathrm{ST}}$ analyses.
Although AMOVA partition of the total variance among the eight subpopulations indicated that the greatest variation occurred within the complete population, most of the remaining variation was due to differences between sampling sites rather than to withinsite variability (Table 4). Nevertheless, within-site variability was highly significant. This could result from differences in the development of epidemics in adjacent greenhouses, as suggested by the substantial differences found in the numbers of haplotypes (Table 1) and contrasted patterns of dominant haplotypes (Table 2) observed in adjacent greenhouses. It could also be due to differences between isolates collected on diseased plants and in the air.

Higher genetic diversity in populations from air than from diseased plants. Under the hypothesis that airborne inoculum in a greenhouse is mostly provided by secondary inoculum produced on diseased plants, the population structure of the air samples should be similar to that of the plant samples and each set of air

TABLE 2. Distribution of haplotypes represented by several isolates of Botrytis cinerea sampled from the air and from diseased plants in four greenhouses on two sites in southern France

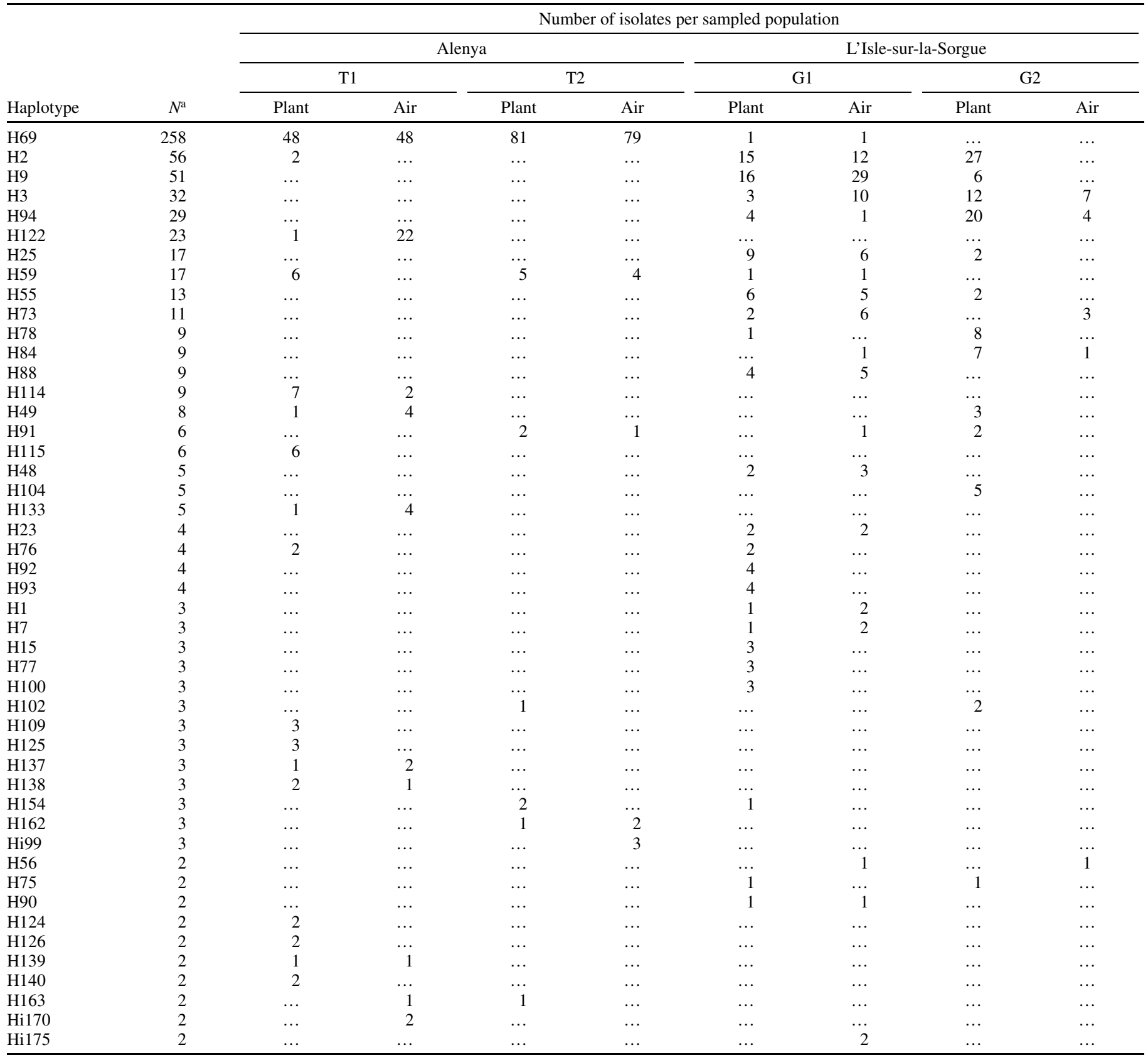

a Total number of isolates. 
and plant samples should share the same dominant haplotypes. In accordance with this hypothesis, the most predominant haplotype (H69) was observed at similar frequencies from air and plant subpopulations in three different greenhouses (Table 2). Other predominant haplotypes occurring in the two greenhouses of L'Isle-sur-la-Sorgue (H2, H9, H3, and H94) were also observed both in the air and on diseased plants in six of eight possible cases. However, examining individual greenhouses on both sampling sites (Table 5) showed that the proportion of haplotypes present both in the air and on plants was only 23 to $68 \%$ among those represented by two or more isolates and 14 to $29 \%$ if single haplotypes were also considered, suggesting that the air and plant subpopulations were not tightly related. Thus, the relatedness of subpopulations was formally tested using population genetics tools.

Pairwise $\mathrm{F}_{\mathrm{ST}}$ values computed between the air and plant subpopulations showed a significant differentiation in three of the four greenhouses (Table 3). Despite overall high values of the linkage disequilibrium index $r_{\mathrm{d}}$, indicating a high level of clonality in all subpopulations, differences between air and plant subpopulations were also revealed by the analysis of allelic diversity (Table 6). The number of alleles per locus was larger in air than in plant subpopulations for all but two loci (Bc4 and $\mathrm{Bc} 7)$ and total allelic richness $\left(\mathrm{N}_{\mathrm{a}}\right)$ was significantly higher $(P=0.037)$. In three greenhouses, the range of allele sizes was also wider in air subpopulations for at least six of the nine loci, pointing to a greater diversity among isolates collected from the air. This was confirmed by an examination of Nei's diversity index, which was systematically higher for the air subpopulation of every greenhouse (Table 6).

\section{DISCUSSION}

The present study has revealed the consistent occurrence of predominant genetic profiles among a large number of $B$. cinerea isolates characterized from four commercial greenhouses in southern France. These results contrast sharply with those of previous studies on this fungus conducted with the same genotyping tools in different agricultural contexts. In such studies using the microsatellite markers developed by Fournier et al. (15), the ratio of the number of distinct haplotypes over the total number of characterized isolates varied from 0.37 to 1.00 (Table 7). In the present study, this ratio was strikingly low, with a value of 0.16 , reflecting the presence of large numbers of isolates with identical genotypic profiles. This situation may be due to the specificity of the environment where our study was conducted. In contrast to most other studies cited in Table 7, the present study was focused on a single host species grown in a greenhouse production system, and samples were taken only once from each site. Contrary to openfield situations, where microclimatic conditions can vary widely over time, conditions in a greenhouse usually remain conducive to rapid development of the fungus over long periods of time during the cropping season (20). Furthermore, the management of a greenhouse tomato crop provides susceptible plant tissue throughout the growing season, allowing the pathogen to go rapidly through numerous successive cycles of asexual reproduction (tissue colonization, sporulation, and dissemination) during several months $(6,7)$. The populations characterized in our study presumably resulted from such successive disease cycles, because sampling was carried out toward the end of the growing season and a very

TABLE 3. Pairwise comparisons $\left(F_{\mathrm{ST}}\right)$ of eight Botrytis cinerea subpopulations sampled from diseased tomato plants and from the air in four greenhouses (T1, T2, $\mathrm{G} 1$, and G2) on two sites in southern France ${ }^{\mathrm{a}}$

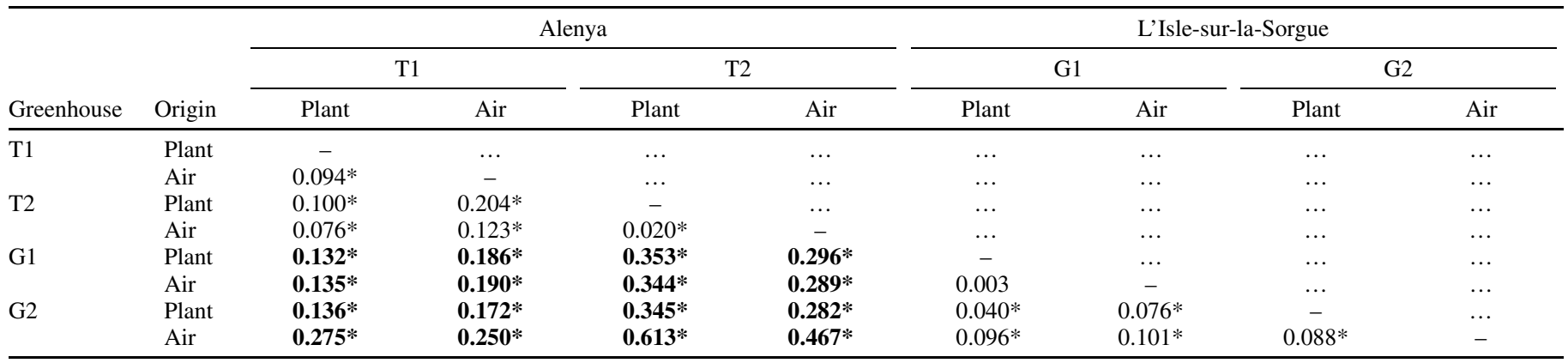

a Asterisks $(*)$ indicate significant genetic differentiation at the 5\% level (assessed after 1,023 permutations and progressive Bonferroni correction). Numbers in bold, indicating comparisons of subpopulations from different sites, show higher $F_{\mathrm{ST}}$ values (one exception) than comparisons of subpopulations from the same site.

TABLE 4. Hierarchical analysis of molecular variance, with sampling site as a grouping factor, in a population of 712 Botrytis cinerea isolates collected from two sites in southern France

\begin{tabular}{lrccrc}
\hline Source of variation & df & Sum of squares & Variance component & Variation $(\%)$ & $P$ value \\
\hline Among sites & 1 & 140.542 & 0.360 & 18.10 & 0.032 \\
Among subpopulations within a site & 6 & 75.967 & 0.129 & 6.50 & $<0.0001$ \\
Within population & 704 & $1,055.037$ & 1.499 & 75.40 & $<0.0001$ \\
\hline
\end{tabular}

TABLE 5. Compared occurrence of haplotypes in air and plant samples of Botrytis cinerea isolates collected from four commercial tomato greenhouses

\begin{tabular}{|c|c|c|c|c|c|}
\hline \multirow[b]{2}{*}{ Greenhouse } & \multicolumn{2}{|c|}{ Number of haplotypes per greenhouse } & \multicolumn{3}{|c|}{ Haplotypes present both on plants and in the air of a given greenhouse } \\
\hline & Total & Multiple occurrence $^{\mathrm{a}}$ & Number & Total haplotypes $(\%)^{\mathrm{b}}$ & Multiply-occurring haplotypes $(\%)^{\mathrm{c}}$ \\
\hline $\mathrm{T} 1$ & 40 & 18 & 8 & 20 & 44 \\
\hline $\mathrm{T} 2$ & 23 & 6 & 4 & 17 & 67 \\
\hline G2 & 21 & 13 & 3 & 14 & 23 \\
\hline
\end{tabular}

${ }^{\text {a }}$ Haplotypes represented by two or more isolates in a given greenhouse.

${ }^{\mathrm{b}}$ Percentage of the total number of haplotypes in a greenhouse that are present both on plants and in the air.

${ }^{c}$ Percentage of the number of haplotypes in a greenhouse that are present both on plants and in the air among those that are represented by two or more isolates in that greenhouse. 
high proportion of stem lesions (estimated to $\approx 95 \%$ ) showed signs of past or ongoing sporulation. The hypothesis of a specific environmental effect is reinforced by our observation of a greater level of clonality in the populations of the Alenya site where climate is more humid (due to frequent ingression of moist marine air) and, thus, more conducive to disease development and sporulation by the pathogen $(9,29)$. Furthermore, the microclimate in unheated tunnels such as those of the Alenya site is likely to be more humid than that in heated glasshouses such as those of the other sampling site (7). Contrary to the situation of our study, concomitance of a disease-conducive microclimate and the presence of susceptible plant tissue may have been sporadic for the open-field environments cited in Table 7. This can be exemplified by the situation in the vineyard. Damaging outbreaks of gray mold in vineyards occur mainly during the few weeks that precede grape harvest, despite a relatively constant presence of airborne conidia revealed by aerobiological surveys during the grape cycle (32). These outbreaks are linked to an increase in grapevine susceptibility and to the concomitant occurrence of rainy conditions, which allow the late onset of classical polycyclic epidemics and result in high spore concentrations before grape harvest $(10,32)$.

A second striking result of the present study stems from the comparison of populations sampled simultaneously from the air and from diseased plants at each site. Contrary to our initial hypothesis that the airborne inoculum in the somewhat confined environment of greenhouse production would essentially originate from sporulation on diseased plants, our observation of differ- ences between air and plant subpopulations suggested a nonnegligible contribution of external inoculum. Indeed, the idea that the air spora inside a greenhouse may be sporadically enriched by the entry of external inoculum would be compatible with the observed higher level of allelic diversity in our air samples (Table 6). Exchange of air between the inside and the outside of a greenhouse was shown to occur through passive ventilation $(4,12)$, resulting in possible exchanges of inoculum with the outside environment $(5,22,24)$.

The contrast between the high level of diversity previously reported for various environments and the high level of clonality consistently observed in the present study is compatible with the hypotheses that (i) $B$. cinerea may occur as a highly diverse population at a global scale, which is widely dispersed by abundant airborne inoculum, and (ii) specific environments may foster the selection of certain strains, which become gradually dominant in the local subpopulation. Although $B$. cinerea is considered to be a highly multitrophic fungus, capable of developing on a wide variety of substrates and pathogenic to $>200$ plant species, it is not unlikely that some strains may have a better fitness than others when developing on specific host plants such as tomato. Some level of host specificity has been suggested in a comparison of $B$. cinerea populations isolated from grapes and bramble (14) and in a subpopulation in strawberry fields in Germany (23). The formal demonstration of a gradual selection of strains in a commercial tomato greenhouse would require repeated substantial sampling of populations over a cropping season. Future work could also address the possible existence of other types of en-

TABLE 6. Allelic diversity in populations of Botrytis cinerea sampled from the air and from diseased plants in four commercial tomato greenhouses on two sites in southern France

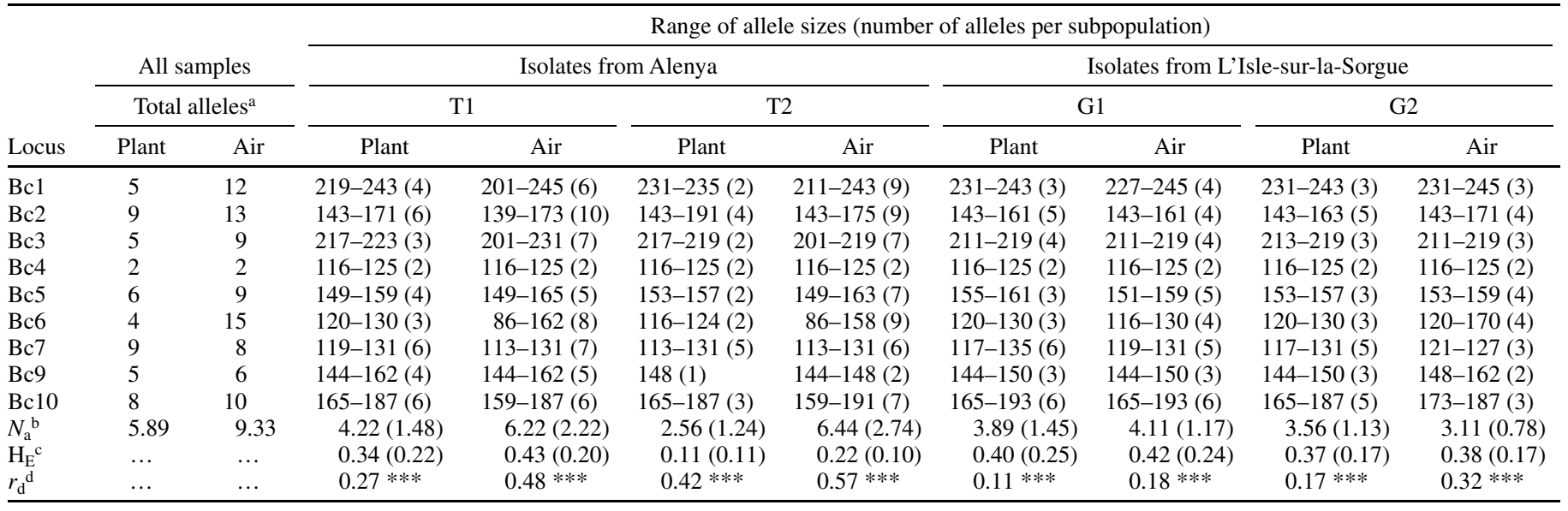

a Total number of alleles from isolates from all samples.

${ }^{\mathrm{b}}$ Mean number of alleles per locus (standard deviation in parentheses).

c Nei's index (standard deviation in parentheses).

${ }^{\mathrm{d}}$ Measure of the linkage disequilibrium. Observed values were compared with the results of 1,000 randomizations of alleles. Asterisks (***) indicate statistical significance at $P=0.001$.

TABLE 7. Proportion of distinct haplotypes among populations of Botrytis cinerea isolates characterized with microsatellite markers

\begin{tabular}{|c|c|c|c|c|c|c|c|}
\hline Location of study & Origin of isolates & $\begin{array}{c}\text { Micro- } \\
\text { satellites }^{\mathrm{a}}\end{array}$ & $\begin{array}{c}\text { Number of } \\
\text { sampled } \\
\text { subpopulations }\end{array}$ & $\begin{array}{l}\text { Number of } \\
\text { isolates }\end{array}$ & $\begin{array}{c}\text { Number of } \\
\text { distinct } \\
\text { haplotypes }\end{array}$ & $\begin{array}{c}\text { Proportion } \\
\text { of } \\
\text { haplotypes }\end{array}$ & Reference \\
\hline France & Air, tomato & 9 & 8 & 712 & 112 & 0.16 & Present study \\
\hline Hungary & Rape, raspberry, strawberry & 5 & 2 & 92 & 35 & 0.38 & 13 \\
\hline Bangladesh & Chickpea & 9 & 4 & 146 & 69 & 0.47 & 19 \\
\hline South Africa & Rooibos & 7 & 5 & 206 & 100 & 0.49 & 36 \\
\hline Hungary & Grapes & 5 & 12 & 109 & 55 & 0.50 & 34 \\
\hline United Kingdom & Blackberry, dandelion, primrose, strawberry & 9 & - & 243 & 243 & 1.00 & 30 \\
\hline
\end{tabular}

${ }^{a}$ Number of microsatellites used among the nine microsatellites described by Fournier et al. (15).

${ }^{b}$ Ratio of the number of distinct haplotypes over the total number of isolates characterized in the study. 
vironments capable of fostering such phenomena (in natural or anthropized contexts), because such sites could constitute privileged zones for rapid evolution of both environmental fitness and pathogenicity-related traits of this fungus (26).

In conclusion, our results are compatible with the entry in the greenhouse of substantial amounts of inoculum from the outside environment but they also highlight the importance of secondary inoculum produced within the crop, as shown previously in experimental conditions (6). This confirms, in conditions of commercial production, that sporulation could be an important target for disease management strategies in the greenhouse.

\section{ACKNOWLEDGMENTS}

This work was supported, in part, by a research grant from the French National Institute for Agricultural Research (INRA). We thank D. Andurand and C. Troulet for their help with sampling and their contribution to isolate genotyping.

\section{LITERATURE CITED}

1. Agapow, P. M., and Burt, A. 2001. Indices of multilocus linkage disequilibrium. Mol. Ecol. Notes 1:101-102.

2. Asadollahi, M., Fekete, E., Karaffa, L., Flipphi, M., Arnyasi, M., Esmaeili, M., Vaczy, K. Z., and Sandor, E. 2013. Comparison of Botrytis cinerea populations isolated from two open-field cultivated host plants. Microbiol. Res. 168:379-388.

3. Beever, R. E., and Weeds, P. L. 2004. Taxonomy and genetic variation of Botrytis and Botryotinia. Pages 29-52 in: Botrytis: Biology, Pathology and Control. Y. Elad, B. Williamson, P. Tudzynski, and N. Delen, eds. Kluwer Academic Publishers, Dordrecht, The Netherlands.

4. Boulard, T., and Baille, A. 1995. Modelling of air exchange rate in a greenhouse equipped with continuous roof vents. J. Agric. Eng. Res. 61:37-48.

5. Boulard, T., Chave, M., Fatnassi, H., Poncet, C., and Roy, J. C. 2008. Botrytis cinerea spore balance of a greenhouse rose crop. Agric. For. Meterol. 148:504-511.

6. Decognet, V., Bardin, M., Trottin-Caudal, Y., and Nicot, P. C. 2009. Rapid change in the genetic diversity of Botrytis cinerea populations after the introduction of strains in a tomato glasshouse. Phytopathology 99:185193.

7. Dik, A. J., and Wubben, J. P. 2004. Epidemiology of Botrytis cinerea diseases in greenhouses. Pages 319-333 in: Botrytis: Biology, Pathology and Control. Y. Elad, B. Williamson, P. Tudzynski, and N. Delen, eds. Kluwer Academic Publishers, Dordrecht, The Netherlands.

8. Edwards, S. G., and Seddon, B. 2001. Selective media for the specific isolation and enumeration of Botrytis cinerea conidia. Lett. Appl. Microbiol. 32:63-66.

9. Elad, Y., Shtienberg, D., Yunis, H., and Mahrer, Y. 1992. Epidemiology of grey mould, caused by Botrytis cinerea in vegetables greenhouses. Pages 147-159 in: Recent Advances in Botrytis Research. K. Verhoeff, N. E. Malathrakis, and B. Williamson, eds. Pudoc Scientific Publishers, Wageningen, The Netherlands.

10. Elmer, P. A. G., and Michailides, T. J. 2004. Epidemiology of Botrytis cinerea in orchard and vine crops. Pages 243-272 in: Botrytis: Biology, Pathology and Control. Y. Elad, B. Williamson, P. Tudzynski, and N. Delen, eds. Kluwer Academic Publishers, Dordrecht, The Netherlands.

11. Excoffier, L., Laval, G., and Schneider, S. 2005. Arlequin ver. 3.0: an integrated software package for population genetics data analysis. Evol. Bioinf. Online 1:47-50.

12. Fatnassi, H., Leyronas, C., Boulard, T., Bardin, M., and Nicot, P. 2009. Dependence of greenhouse tunnel ventilation on wind direction and crop height. Biosyst. Eng. 103:338-343.

13. Fekete, E., Fekete, E., Irinyi, L., Karaffa, L., Arnyasi, M., Asadollahi, M., and Sandor, E. 2012. Genetic diversity of a Botrytis cinerea cryptic species complex in Hungary. Microbiol. Res. 167:283-291.

14. Fournier, E., and Giraud, T. 2008. Sympatric genetic differentiation of a generalist pathogenic fungus, Botrytis cinerea, on two different host plants, grapevine and bramble. J. Evol. Biol. 21:122-132.

15. Fournier, E., Giraud, T., Loiseau, A., Vautrin, D., Estoup, A., Solignac, M., Cornuet, J. M., and Brygoo, Y. 2002. Characterization of nine polymorphic microsatellite loci in the fungus Botrytis cinerea (Ascomycota). Mol. Ecol. Notes 2:253-255.

16. Goyeau, H., Halkett, F., Zapater, M.-F., Carlier, J., and Lannou, C. 2007. Clonality and host selection in the wheat pathogenic fungus Puccinia triticina. Fungal Genet. Biol. 44:474-483.

17. Guérin, F., and Le Cam, B. 2004. Breakdown of the scab resistance gene $\mathrm{Vf}$ in apple leads to a founder effect in population of the fungal pathogen Venturia inaequalis. Phytopathology 94:364-369.

18. Holz, G., Coertze, S., and Williamson, B. 2004. The ecology of Botrytis on plant surfaces. Pages 9-27 in: Botrytis: Biology, Pathology and Control. Y. Elad, B. Williamson, P. Tudzynski, and N. Delen, eds. Kluwer Academic Publishers, Dordrecht, The Netherlands.

19. Isenegger, D. A., Macleod, W. J., Ford, R., and Taylor, P. W. J. 2008. Genotypic diversity and migration of clonal lineages of Botrytis cinerea from chickpea fields of Bangladesh inferred by microsatellite markers. Plant Pathol. 57:967-973.

20. Jewett, T. J., and Jarvis, W. R. 2001. Management of the greenhouse microclimate in relation to disease control: a review. Agronomie 21:351366.

21. Karchani-Balma, S., Gautier, A., Raies, A., and Fournier, E. 2008. Geography, plants, and growing systems shape the genetic structure of Tunisian Botrytis cinerea populations. Phytopathology 98:1271-1279.

22. Korolev, N., Katan, T., and Elad, Y. 2006. Use of selenate-resistant strains as markers for the spread and survival of Botrytis cinerea under greenhouse conditions. Phytopathology 96:1195-1203.

23. Leroch, M., Plesken, C., Weber, R. W. S., Kauff, F., Scalliet, G., and Hahn, M. 2013. Gray mold populations in German strawberry fields are resistant to multiple fungicides and dominated by a novel clade closely related to Botrytis cinerea. Appl. Environ. Microbiol. 79:159-167.

24. Leyronas, C., Fatnassi, H., Bardin, M., Boulard, T., and Nicot, P. C. 2011. Modelling Botrytis cinerea spore exchanges and production in unheated greenhouses. J. Plant Pathol. 93:407-414.

25. Meirmans, P. G., and Van Tienderen, P. H. 2004. Genotype and Genodive: two programs for the analysis of genetic diversity of asexual organisms. Mol. Ecol. Notes 4:792-794.

26. Morris, C. E., Bardin, M., Kinkel, L. L., Moury, B., Nicot, P. C., and Sands, D. C. 2009. Expanding the paradigms of plant pathogen life history and evolution of parasitic fitness beyond agricultural boundaries. PLoS Pathol. 5:e1000693.

27. Nei, M., ed. 1987. Molecular Evolutionary Genetics. Columbia University Press, New York.

28. Nicot, P. C., Mermier, M., Vaissiere, B. E., and Lagier, J. 1996. Differential spore production by Botrytis cinerea on agar medium and plant tissue under near-ultraviolet light-absorbing polyethylene film. Plant Dis. 80:555-558.

29. O'Neill, T. M., Shtienberg, D., and Elad, Y. 1997. Effect of some host and microclimate factors on infection of tomato stems by Botrytis cinerea. Plant Dis. 81:36-40.

30. Rajaguru, B. A. P., and Shaw, M. W. 2010. Genetic differentiation between hosts and locations in populations of latent Botrytis cinerea in southern England. Plant Pathol. 59:1081-1090.

31. Rice, W. R. 1989. Analyzing tables of statistical tests. Evolution 43:223225.

32. Rodriguez-Rajo, F. J., Jato, V., Fernandez-Gonzalez, M., and Aira, M. J. 2010. The use of aerobiological methods for forecasting Botrytis spore concentrations in a vineyard. Grana 49:56-65.

33. Stoddart, J. A., and Taylor, J. F. 1988. Genotypic diversity: estimation and prediction in samples. Genetics 118:705-711.

34. Vaczy, K. Z., Sandor, E., Karaffa, L., Fekete, E., Fekete, E., Arnyasi, M., Czegledi, L., Kovics, G. J., Druzhinina, I. S., and Kubicek, C. P. 2008. Sexual recombination in the Botrytis cinerea populations in Hungarian vineyards. Phytopathology 98:1312-1319.

35. Weir, B. S., and Cockerman, C. C. 1984. Estimating $F$-statistics for the analysis of population structure. Evolution 38:1358-1370.

36. Wessels, B. A., Lamprecht, S. C., Linde, C. C., Fourie, P. H., and Mostert, L. 2013. Characterization of the genetic variation and fungicide resistance in Botrytis cinerea populations on rooibos seedlings in the Western Cape of South Africa. Eur. J. Plant Pathol. 136:407-417. 